\title{
Occupational exposure to dust: inflammation and ischaemic heart disease
}

Department of Occupational Health, Swedish National Institute for Working Life, S-171 84, Solna, Sweden

B Sjögren

Accepted 23 January 1997
Bengt Sjögren
The present review expands the hypothesis and links occupational exposure to inhaled particles to the occurrence of IHD. Long term inhalation of particles from the work environment will hypothetically create a low grade inflammation, which is associated with an increase in plasma fibrinogen. The high concentrations of fibrinogen will then increase the risk of myocardial infarction and IHD. This review and hypothesis are parts of a large project on work organisation, lipids, and fibrinogen (WOLF) currently in progress at the National Institute of Working Life and the Karolinska Institute.

One model for this link between inhaled particles and IHD is cigarette smoke. Inhalation of particles and gases from cigarette smoke is associated with an increased number of neutrophils in peripheral blood, ${ }^{6}$ an increased concentration of fibrinogen, ${ }^{7}$ and higher incidence of ischaemic heart disease. ${ }^{2}$ However, the increased risk for IHD among smokers is not totally explained by the increased concentrations of fibrinogen. ${ }^{2}$

A literature search of case-control studies on IHD in specific exposures to dust was performed in Medline during 1990-6 and NIOSHTIC during 1986-96. These studies together with some other studies of specific exposures to dust or occupations are presented and the hypothesis is further discussed.

\section{Quartz}

A Swedish case-control study of 26847 men who had had myocardial infarctions and for each case two controls were selected from the study base through random sampling, stratified by age, county, and socioeconomic group. The second highest risk was found among stonecutters and carvers (relative risk (RR) 1.9, 95\% confidence interval $(95 \% \mathrm{CI}) 1.1$ to 3.4$)$. This high risk could not be explained by differences in smoking habits. ${ }^{8}$

A case-control study was performed within a cohort of 3971 white South African gold miners. The RR for IHD after 10 years of underground service was $1.5(P=0.004)$ after adjustment for blood pressure, smoking, and body mass index. ${ }^{9}$ However, this result could not be repeated in a case-control study within a larger cohort of 4925 gold miners. $^{10}$

\section{Asbestos}

Ischaemic heart disease was studied in a cohort of 1725 Swedish male shipyard workers exposed to asbestos. The analyses were stratified for age and smoking. Men with asbestosis or suspected asbestosis had a significantly 
higher risk (RR 3.1, 95\% CI 1.5 to 6.4 ) of dying from IHD than did men without asbestosis. Men with impaired lung function also had a significantly increased risk of dying from IHD. ${ }^{11}$

An increased mortality due to diseases of the circulatory system has also been found among workers exposed to chrysotile asbestos in the United States (standardised mortality ratio (SMR) 1.3, P<0.05). The smoking habits in this cohort were about the same as in the control group of United States men. ${ }^{12}$

\section{Polycyclic aromatic hydrocarbons}

Chimney sweeps are exposed to polycyclic aromatic hydrocarbons (PAHs). Both a Danish and a Swedish study of chimney sweeps found an excess mortality from IHD. The Danish cohort consisted of 713 chimney sweeps and used employed men as controls (SMR 2.2). ${ }^{13}$ The Swedish cohort consisted of more than 5000 chimney sweeps and used national death rates as reference. The SMR was 1.2 (95\% CI 1.0 to 1.3 ) after adjustment for smoking habits. ${ }^{14}$

A case-control study in a large aluminium production complex was performed in Canada. There was a significantly higher risk of IHD among blue collar workers, in particular among prebake potroom workers (odds ratio (OR) $2.3,95 \%$ CI 1.3 to 4.0 ) after adjustment for smoking, hypertension, hyperglycaemia, hypercholesterolaemia, and obesity. These potroom workers were exposed to PAHs but also to several other air pollutants. ${ }^{15}$ A Norwegian study of potroom workers found an association between exposure to tar and atherosclerotic disease. $^{16}$

Car mechanics are exposed to PAHs but also to anticorrosives, solvents, and mineral oils. A cohort of Danish car mechanics were compared with skilled workers. The mechanics had a higher risk for IHD (SMR 1.2, 95\% CI 1.0 to 1.5). Smoking was an unlikely confounder as the SMR for lung cancer was $1.0 .^{17}$

\section{Arsenic}

Kristensen presented a comprehensive review on chemical factors and cardiovascular diseases in $1989 . .^{18}$ Some studies of cohorts exposed to arsenic have had increased SMRs compared with the general population. A casecontrol study showed an RR of 2.1 (90\% CI 1.2 to 3.5) for heart disease. This study showed a dose-response pattern. ${ }^{19}$

\section{Beryllium}

Mortality was studied in a cohort of 3055 workers exposed to beryllium. A significantly increased $\mathrm{RR}$ was found for heart diseases (SMR 1.13, P<0.05). A higher risk was found among the workers with employment of less than five years (SMR 1.10) as well as among those employed for five years or more (SMR 1.29). The smoking habits were about the same as in the control group of United States men. ${ }^{20}$

\section{Lead}

In his review, Kristensen concluded that there is a causal relation between lead exposure and blood pressure and there is an increased incidence of cerebrovascular diseases among workers occupationally exposed to lead. ${ }^{18}$ If workers exposed to lead have IHD it might be an expression of high blood pressure.

\section{Farmers}

Farmers are exposed to organic dust containing several components-for example, endotoxin, mites, and moulds. This exposure causes allergic and inflammatory respiratory diseases such as asthma, chronic bronchitis, and allergic alveolitis. ${ }^{21}$

Finnish farmers had the highest mean concentration of plasma fibrinogen $(3.07 \mathrm{~g} / \mathrm{l})$ when compared with blue collar workers (3.03 $\mathrm{g} / \mathrm{l})$ and white collar workers $(2.98 \mathrm{~g} / \mathrm{l})$. The difference between farmers $(n=841)$ and white collar workers $(n=837)$ was small but significant. ${ }^{22}$

In another Finnish study female farmers had a higher risk of coronary deaths when compared with white collar workers (RR 1.7, 95\% CI 1.0 to 2.8 ), after adjustment for age, smoking serum cholesterol, and blood pressure. However this was not found in male farmers (RR 0.9, 95\% CI 0.7 to 1.2 ). ${ }^{23}$

Swedish farm managers and supervisors had an increased risk of myocardial infarction ( $R R$ $1.6,95 \%$ CI 1.0 to 2.6 ), after adjustment for age, county, and socioeconomic group. ${ }^{8}$ However, this was not supported by a Swedish study of 60000 farmers and 2.8 million economically active controls. The morbidity was studied from the statistics collected from the counties responsible for hospitals in Sweden for the period 1978-83. Male farmers had fewer cardiovascular diseases (SMR 0.74, 95\% CI 0.70 to 0.77 ) but the female farmers did not differ from the controls (SMR 1.01, 95\% CI 0.90 to 1.13$).^{24}$ Swedish farmers are known to smoke less than average but smoking was not adjusted for in the analysis. The adjustment for county and socioeconomic group might reduce the effect that people in the countryside are less prone to seek medical care than people in big cities. Self employed people and entrepreneurs are also less inclined to make use of medical services. ${ }^{24}$ Thus, several factors might explain the differences between the two Swedish studies.

\section{Sawyers}

In the Swedish case-control study already described $^{8}$ the third highest risk was found among frame and circular sawyers and planers (RR 1.7, 95\% CI 1.0 to 3.0), who are mainly exposed to wood dust. The risk estimate was adjusted for age, county, and socioeconomic group.

\section{Paper and paper pulp workers}

Health risks among paper and paper pulp workers have recently been reviewed by Torén and coworkers. ${ }^{25}$ These workers are exposed to several more or less irritant gases such as chlorine, chlorine dioxide, sulfur dioxide, and terpenes as well as paper dust. Exposure to high concentrations of paper dust ( $>5 \mathrm{mg} / \mathrm{m}^{3}$ ) has caused impaired lung function. ${ }^{25}$ In the 
study by Hammar and coworkers ${ }^{8}$ increased risks of myocardial infarctions were found for paper and paperboard workers (RR 1.6, 95\% CI 1.0 to 2.7) and paper pulp workers (RR 1.3, $95 \%$ CI 1.0 to 1.7 ) after adjustment for age, county, and socioeconomic group.

\section{Welders}

Welders are exposed to several gases and respirable particles. Chronic bronchitis and impaired lung function have been found among these workers. ${ }^{26}$ An increased risk of myocardial infarction has been found among welders and flame cutters (RR 1.1, 95\% CI 1.0 to 1.3$){ }^{8}$ When socioeconomic group is taken into account the $R R$ was 1.0 (95\% CI, 0.9 to $1.2)$. It could be argued that an adjustment for socioeconomic group results in overmatching. This means that welders exposed to particles are compared with occupational groups with the same socioeconomic stratum and these groups contain a large proportion of workers who are exposed to high concentrations of particles.

A cross sectional study of welders working in stainless steel was recently reported at the 25 th International Congress on Occupational Health. The welders $(n=240)$ were compared with 1159 randomly selected men. An increased risk was found for symptoms of angina pectoris after adjustment for age and smoking habits (RR 2.6, 95\% CI 1.2 to 5.7). ${ }^{27}$

\section{Discussion}

Most previous cohort studies of workers exposed to dust have shown a decreased risk for IHD when these groups have been compared with national death rates. This decreased risk is well known as the healthy worker effect and is explained by the lack of comparability between the particular group of workers and the general population which will include sick and disabled people unable to work. ${ }^{28}$ This is the explanation why IHD has seldom been studied with proper designs in the field of occupational medicine. On the other hand the relation between a decreased lung function and IHD has been studied by several groups, without considering specific exposures. Thus occupational exposure to dust and IHD have not been focused at the same time.

Some inhaled particles - for example, quartz and asbestos - are known to induce an inflammatory process with fibrosis in the lungs. It seems obvious that particles have different abilities to provoke a low grade inflammation in the lungs.

A recently published Finnish cohort study of 19444 randomly selected men and women were followed up for 13 years. People with chronic bronchitis, defined as cough with phlegm during most days or nights for at least three months a year, had a higher risk for coronary disease and coronary deaths. The risk ratio among men was 1.4 (95\% CI 1.2 to 1.6$)$ for coronary disease and $1.6(95 \%$ CI 1.3 to 1.9) for coronary deaths, after adjustment for smoking, serum cholesterol, and systolic blood pressure. The corresponding risk ratios for women were $1.3(95 \% \mathrm{CI} 1.0$ to 1.7$)$ for coronary disease and 1.4 (95\% CI 0.9 to 2.2 ) for coronary deaths. This pattern was found for both white and blue collar workers. ${ }^{29}$ It is generally accepted that long term industrial exposure to dusts and irritant gases will lead to the development of cough and sputum. ${ }^{30}$ It might be possible that chronic bronchitis caused by inhalation of industrial dusts is associated with IHD.

Several studies have found a relation between a decreased lung function expressed as vital capacity, ${ }^{31}$ forced expiratory volume in one second $\left(\mathrm{FEV}_{1}\right){ }^{32} \mathrm{FEV} \%{ }^{33}$ or peak expiratory flow $^{34}$ and IHD. A relation between decreased lung function (vital capacity (VC) and $\mathrm{FEV}_{1}$ ) and increased concentrations of fibrinogen has also been shown in a study of 788 Swedish men. ${ }^{35}$

Lower social classes have in general higher mean concentrations of plasma fibrinogen compared with higher social classes ${ }^{7637}$ and this has been suggested as the explanation of the class differences of IHD. It could be argued that the proportion of people exposed to particles is higher in lower than in higher social classes. The source of this exposure to particles could be environmental as well as occupational. It has also been shown that manual workers have higher concentrations of fibrinogen than non-manual workers. ${ }^{38}$

Hepatocytes are stimulated to secrete fibrinogen by interleukin- 6 (IL-6).$^{39}$ The serum concentrations of IL-6 increased in previously non-exposed subjects after the inhalation of swine dust. ${ }^{40}$ Welders exposed to zinc containing welding fumes increased their concentrations of IL-6 in bronchoalveolar lavage. ${ }^{41}$ An increase of IL-6 in nasal lavage fluid has also been found in volunteers exposed to fumes generated in a sawmill. ${ }^{42}$ Thus exposure to different agents in some of the occupations associated with an increased risk of IHD (farmers, welders, and sawyers) can result in increased concentrations of IL- 6 in some biological fluids. These concentrations might hypothetically stimulate the liver cells to secrete more fibrinogen.

$\alpha 1$-Antitrypsin is also one of the acute phase responders. High concentrations of $\alpha 1$ antitrypsin have been found among Canadian non-cedar sawmill workers. ${ }^{43}$ In some diseases there is a close relation between plasma concentrations of $\alpha 1$-antitrypsin and fibrinogen, ${ }^{44}$ suggesting that exposure to wood dust may increase the plasma concentrations of fibrinogen.

During the 1970s and 1980s there has been a decline in IHD mortality in several western countries. ${ }^{45}$ This decline may be explained to some extent by less air polluted urban ${ }^{5}$ and work environments.

Other chronic inflammations with a concomitant increase in fibrinogen would theoretically increase the occurrence of IHD. It has recently been shown that infections of Helicobacter pylori and Chlamydia pneumoniae are both associated with increased concentrations of plasma fibrinogen and an increased risk of IHD. ${ }^{46}$ 
Rheumatoid arthritis is a chronic inflammatory disease of the joints. Some cohort studies have found an increased number of cardiovascular deaths among such patients. ${ }^{47-49}$ Monson and $\mathrm{Hall}^{48}$ showed an increased number of deaths due to IHD despite the use of aspirin. Aspirin may be the reason why the results from all studies are not consistent.

This hypothesis can be tested comparing the concentrations of fibrinogen in workers exposed and non-exposed to particles with control for other possible confounders such as smoking habits. This could possibly be performed in some of the older studies with large populations.

I appreciate very much the comments on the manuscript by Ingvar Lundberg, Anthony Seaton, and Peter Westerholm. I thank Ulf Palmqvist for his extensive searches in Medline and NIOSHTIC.

1 Meade TW, Mellows S, Brozovic M, Miller GJ, Chakrabarti RR, North WRS, et al. Haemostatic function and ischaemic heart disease: principle results of the Nortwick Park heart study. Lancet 1986;ii:533-7.

2 Yarnell JWG, Baker IA, Sweetnam PM, Bainton D, O'Brien JR, Whitehead PJ, Elwood PC. Fibrinogen, viscosity, and white blood cell count are major risk factors for ischemic heart disease. Circulation 1991;83:836-44.

3 Folsom AR, Qamhieh HT, Flack JM, Hilner JE, Liu K, Howard BV, Tracy RP. Plasma fibrinogen: levels and correlates in young adults. Am $\mathcal{F}$ Epidemiol 1993;138:1023-36.

4 Dinarello CA. The acute phase response. In: Wyngaarden JB, Smith LH Jr, Bennett JC, eds. Cecil's textbook of JB, Smith LH Jr, Bennett JC, eds. Cecil's textbook
medicine. 19th ed. Philadelphia: WB Saunders, 1992.

5 medicine. 19th ed. Philadelphia: WB Saunders, 1992. air pollution and acute health effects. Lancet 1995;345: air poll

6 Petitti DB, Kipp H. The leukocyte count: associations with intensity of smoking and persistance of effect after quitting. Am $\mathcal{F}$ Epidemiol 1986;123:89-95.

7 Rosengren A, Wilhelmsen L, Welin L, Tsipogianni A, Teger-Nilsson A-C, Wedel H. Social influences and cardiovascular risk factors as determinants of plasma fibrinogen concentration in a general population sample of middle age men. BMF 1990;300:634-8.

8 Hammar N, Alfredsson L, Smedberg M, Ahlbom A. Large differences in the incidence of myocardial infarction among occupational groups. Scand $\Im$ Work Environ Health 1992;18: 178-85.

9 Wyndham CH, Bezuidenhout BN, Greenacre MJ, SluisCremer GK. Mortality of middle aged white South African cremer GK. Mortality of middle aged white

10 Reid PJ, Sluis-Cremer GK. Mortality of white South African gold miners. Occup Environ Med 1996;53:11-6.

11 Sandén A, Järvholm B, Larsson S. The importance of lung function, non-malignant diseases associated with asbestos, and symptoms as predictors of ischemic heart disease in shipyard workers exposed to asbestos. Br f Ind Med 1993; 50:785-90.

12 Dement JM, Harris RL, Symons MJ, Shy CM. Exposures and mortality among chrysotile asbestos workers. Part II: mortality. Am $\mathcal{F}$ Ind Med 1983;4:421-33.

13 Hansen ES. Mortality from cancer and ischemic heart disease in Danish chimney sweeps: a five-year follow-up. Am $\mathcal{F}$ Epidemiol 1983;117:160-4.

14 Evanoff BA, Gustavsson P, Hogstedt C. Mortality and incidence of cancer in a cohort of Swedish chimney sweeps: an dence of cancer in a cohort of Swedish chimney sweeps:

15 Thériault GP, Tremblay CG, Armstrong BG. Risk of ischemic heart disease among primary aluminum producischemic heart disease among primary alumin

16 Rönneberg A. Mortality and cancer morbidity in workers from an aluminium smelter with prebaked carbon anodes part III: mortality from circulatory and respiratory diseases. Occup Environ Med 1995;52:255-61.

17 Hansen ES. Mortality of auto mechanics. A 10 year followup. Scand $\mathcal{f}$ Work Environ Health 1989;15:43-6.

18 Kristensen TS. Cardiovascular diseases and the work environment. A critical review of the epidemiologic literature on chemical factors. Scand $\mathcal{F}$ Work Environ Health 1989;15:245-64.

19 Axelson O, Dahlgren E, Jansson CD, Rehnlund SO. Arsenic exposure and mortality: a case-referent study from a Swedish copper smelter. Br $¥$ Ind Med 1978;35:8-15.

20 Wagoner JK, Infante PF, Bayliss DL. Beryllium: an etiologic agent in the induction of lung cancer, non-neoplastic respiratory disease, and heart disease among industrially ratory disease, and heart disease among
21 Malmberg $P$. Health effects of organic dust exposure in dairy farmers. $A m \mathcal{F}$ Ind Med 1990;17:7-15.

22 Wilson TW, Kaplan GA, Kauhanen J, Cohen RD, Wu M, Salonen R, Salonen JT. Association betweeen plasma fibrinogen concentration and five socioeconomic indices in the Kuopio ischemic heart disease risk factor study. $A m \mathcal{F}$ Epidemiol 1993;137:292-300.

23 Jousilahti P, Vartiainen E, Tuomilehto J, Puska P. Occupation, fibrinogen, and heart disease. Lancet 1997;349:506.

24 Thelin A. Morbidity in Swedish farmers, 1978-83, according to national hospital records. Soc Sci Med 1991;32:3059.

25 Torén $\mathrm{K}$, Hagberg $\mathrm{S}$, Westberg $\mathrm{H}$. Health effects of working in pulp and paper mills: exposure, obstructive airways diseases, hypersensitivity reactions, and cardiovascular diseases. Am F Ind Med 1996;29:111-22.

26 Sjögren B. Effects of gases and particles in welding and soldering. In: Zenz C, Dickerson OB, Horvath EP, eds. Occupational medicine. 3rd ed. St Louis: Mosby-Year Book, pational medicine.

27 Hilt B, Qvenild T, Römyhr O, Wist Dalsegg R. Cardiovascular morbidity among workers in a stainless steel industry. 25th International Congress on Occupational Health. Solna, Sweden: The Swedish National Institute for Working Life 1996. (OS 408.)

28 McMichael AJ. Standardized mortality ratios and the "healthy worker effect": scratching beneath the surface. $\mathcal{F}$ Occup Med 1976;18:165-8.

29 Jousilahti P, Vartiainen E, Tuomilehto J, Puska P. Symptoms of chronic bronchitis and the risk of coronary disease. Lancet 1996;348:567-72.

30 Morgan WKC. Bronchitis, airways' obstruction and occupation. In: Parkes WR, ed. Occupational lung disorders. 3rd pation. In: Parkes WR, ed. Occupational lung disorders.

31 Kannel WB, Wilson P, Blair SN. Epidemiological assessment of the role of physical activity and fitness in development of cardiovascular disease. Am Heart $f$ 1985;109:87685

32 Hole DJ, Watt GCM, Davey-Smith G, Hart CL, Gillis CR, Hawthorne VM. Impaired lung function and mortality risk in men and women: findings from the Renfrew and Paisley prospective population study. BMF 1996;313:711-5.

33 Beaty TH, Cohen BH, Newill CA, Menkes HA, Diamond EL, Chen CJ. Impaired pulmonary function as a risk factor EL, Chen CJ. Impaired pulmonary function as a

34 Persson C, Bengtsson C, Lapidus L, Rybo E, Thiringer G, Wedel $\mathrm{H}$. Peak expiratory flow and risk of cardiovascular disease and death. Am $\mathcal{F}$ Epidemiol 1986;124:942-8.

35 Korsan-Bengtsen K, Wilhelmsen L, Tibblin G. Blood coagulation and fibrinolysis in a random sample of 788 men 54 years old. II. Relations of the variables to "risk factors" for myocardial infarction. Thrombosis et Diathesis Haemorrhagica 1972;28:99-108.

36 Meade TW, Chakrabarti RR, Haines AP, North WRS, Stirling Y. Characteristics affecting fibrinolytic activity and ling Y. Characteristics affecting fibrinolytic activity and

37 Möller L, Kristensen TS, Hollnagel $H$. Social class and cardiovascular risk factors in Danish men. Scand $\mathcal{F}$ Soc Med 1991;19:116-26.

38 Woodward M, Shewry MC, Smith WCS, Tunstall-Pedoe H. Social status and coronary heart disease: results from the Scottish heart health study. Prev Med 1992;21:136-48.

39 Akira S, Kishimoto T. IL-6 and NF-IL6 in acute-phase response and viral infection. Immunol Rev 1992;127:25-50.

40 Wang Z, Malmberg P, Larsson P, Larsson B-M, Larsson K. Time course of interleukin- 6 and tumor necrosis factor increase in serum following inhalation of swine dust. $A \mathrm{~m} \mathcal{F}$ increase in serum following inhalation of

41 Blanc PD, Boushey HA, Wong H, Wintermeyer SF, Bernstein MS. Cytokines in metal fume fever. Am Rev Respir Dis 1993;147:134-8.

42 Dahlqvist M, Palmberg L, Malmberg P, Sundblad B-M, Ulfvarson U, Wang Z. Acute effects of exposure to air contaminants in a sawmill on healthy volunteers. Occup Environ Health 1996;53:586-90.

43 Ashley MJ, Corey P, Chan-Yeung M. Smoking, dust exposure, and serum a1-antitrypsin. Am Rev Respir Dis 1980;121:783-8.

44 Langley PG, Hughes RD, Rolando N, Williams R. Increased elastase- $\alpha 1$-antitrypsin complex in fulminant hepatic foagulation. Clin Chim Acta 1991;200:211-20.

45 Thom TJ. International mortality from heart disease: rates Thom TJ. International mortality from heart
and trends. Int $₹$ Epidemiol 1989;18:S20-8.

46 Patel P, Mendall MA, Carrington D, Strachan DP, Leatham E, Molineaux N, et al. Association of Helicobacter pylor and Chlamydia pneumoniae infections with coronary hear disease and cardiovascular risk factors. $B M \mathcal{F} 1995 ; 311$ 711-4.

47 Allebeck P. Increased mortality in rheumatoid arthritis. Scand F Rheumatol 1982;11:81-6.

48 Monson RR, Hall AP. Mortality among arthritics. $f$ Chron Dis 1976;29:459-67.

49 Prior P, Symmons DPM, Scott DL, Brown R, Hawkins CF. Cause of death in rheumatoid arthritis. $B r \mathcal{F}$ Rheumatol 1984;23:92-9. 